\title{
On the non-typical cells in the axillary sweat gland
}

\author{
By \\ Kenjiro Yasuda \\ Department of Anatomy, School of Medicine, Keio University, \\ Shinjuku, Tokyo, Japan. \\ (Director: Prof. Dr. T. Taniguchi)
}

\section{Preface}

Schi ef ferdecker (1922) had devided the skin glands into merocrine gland and holocrine gland. He insisted that the merocrine gland consisted of both apocrine gland and eccrine gland. He pointed out the precise difference between apocrine and eccrine glands on the three points, namely the difference in the secretory modus, that in the distribution on the body surface and that in the development. I t o (1949) reported that the histological and cytological studies did not reveal the contradictional results to three items which $\mathrm{Sch}$ i ef $f \mathrm{erde}$ e e r had offered as the standard in the classification of the sweat glands.

Nevertheless, Minamitani (1941-a), Ot a (1950), C ormia and $\mathrm{Ku}$ yke ndall (1955), I to, Narita, Tsu nod a and Shindo (1956) I to and T s u nod a (1956) have reported the occasional occurrence of the non-typical and the mixed sweat glands in the axillary region, perianal and nasal regions respectively. The author has recognized some non-typical cells in the apocrine glandular tubules and tried some histochemical survey on them.

\section{Materials and Methods}

The materials used comprised the skin of the human axilla. The pieces of the tissues which were surgically excised were fixed with absolute alcohol, with absolute acetone, with 'Zenker-formalin, with Levi's solution and the $10 \%$ formalin solution, then embedded in paraffin. The serial sections of $3-5 \mu$ in thickness were prepared 
for the observation. The staining methods were as follows: Heidenhain's iron hematoxylin staining, Thionin staining, PAS staining and alkaline tetrazolium staining methods.

\section{Observations}

There are many kinds of the non-typical or mixed sweat glands in the human axilla. The arbitrary classification of the non-typical glands in this study is as follows:

1) A kind of low cells which break into a line of the apocrine glandular cells, occurring adjacent to the basement membrane.

2) The gland which has two different kinds of the secretory portions. The first portion is lined by the apocrine glandular cells and the second is done by the eccrine glandular cells.

3) The apocrine glands which correspond to the type $B$ gland classified by Min a mita $n$ i (1941-a).

4) The apocrine-like secretory portions, covered seemingly with the dark cells of the eccrine gland which are encountered in the eccrine tubule.

5) The tall lozenge-shaped cells which are discovered between two apocrine glandular cells in the apocrine tubules.

1) A kind of low cells which intervene between two apocrine glandular cells, occurring adjacent to the basement membrane. These cells resemble the clear cells of the eccrine gland. They demonstrate the roundish polygonal, cuboidal and sometimes globular shape. These cells are stained clearly with the iron hematoxylin and strongly with PAS method. The mitochondria are very few in number and the Golgi apparati are rarely encountered. The PAS-positive substances noticed in the cells must be the glycogen, as the reaction disappears after the diastase digestion. Some of these cells stain more remarkably by thionin than both apocrine glandular cells and the clear cells of the eccrine glands. As the treatment of sections in hydrochloric acid (I $\mathrm{N}$ for 3 hours at $37^{\circ} \mathrm{C}$ ) destroyed the basophilia in these cells, the stainability must be chiefly attributable to the cytoplasmic nucleoproteins. This fact is contradictionary to the results obtained in the clear cells of the eccrine glands, which are never provided with the nucleoproteins. Besides, the alkaline tetrazolium reaction is positive exclusively in the non-typical cells mentioned above, but is not clearly distinguishable in the clear cells of the eccrine glands. It is conjectured from the facts described 
above that some of the non-typical cells studied in this paper are different in their nature from the clear cells of the eccrine gland, when examined by histochemical method.

The appearance of these non-typical cells varies according to the size and the form of each glandular buluble, in which they occur. Sometimes they lie with their broad base on the basal membrane, and sometimes they connect with the basement membrane with two or three cytoplasmic stalks protruded towards the basement membrane.

The situation and the distribution of those cells are also full of variety and are divided into four types. 1) The cells belonged to the first item occur adjacent to the basement membrane, between two apocrine glandular cells with columnar shape. They do not face the lumen and look as if they were buried under the apocrine glandular cells, even if they were observed in the serial sections. 2) The cells of the second item arrange themselves between two apocrine glandular cells. They are lower in height than the apocrine glandular cells in the neighbourhood but face the lumen. In the transverse sections of the secretory tubules, the lumen presents irregular shape. The cells of this kind are frequently encountered at the bottom of the epithelial depression. The gradual or rapid decrease in the height of the apocrine glandular cells is recognizable at the surroundings of the non-typical cells. The gradual decrease of the height of the apocrine glandular cells is noticed, with the approach to the nontypical cells, in the secretory tubules which are lined by the low cuboidal apocrine glandular cells and have round-shaped lumen. On the contrary, the rapid decrease is recognizable in the tubules which are arranged by the tall columnar apocrine glandular cells and have star-shaped lumen. 3) The cells in the third item appear in the large glandular tubules with the curved wall, and are often encountered at the apex of the convex surface of the glandular wall. In this case, the non-typical cells protrude into the glandular lumen independently of the regular arrangement of apocrine glandular cell. 4) The cells in the fourth item is found at the bottom of the indented part of the epithelial wall where, correspondingly to the epithelial depression, the glandular wall projects partly towards outside. Some of the non-typical cells face the lumen, but others do not always do so.

There have been several reports on account of these non-typical cells. M in amitani (1941) had devided the apocrine glands into typical, non-typical and mixed forms. The mixed gland on which 
he reported is the eccrine glandular tubules which are partly covered with the apocrine glandular cells, and does not coincide with the cells that the author had demonstrated in this study. Ot a (1950) recognized the admixture of the eccrine-type cells in the apocrine glandular tubules which are lined by the typical apocrine cells, in the axillary skin of the non-osmidrotic man. Ot a took these cells for the clear cells of the eccrine gland. From the results that the author has pointed out, these cells may correspond to what are mentioned in the first item.

As for the distribution of the secretory tubules which contain the non-typical cells, there is a tendency common to the tubules which have the cells of 1-4 types. Generally, these kinds of the non-typical cells appear in such secretory tubules as are well developed and are surrounded by the thick fibrous capsule. The cells of the first item are encountered in the tubules which are lined regularly by the tall apocrine cells and give round profils on the transverse sectioning. The cells of the second, third and fourth items demonstrate themselves in the dilated tubules with curved wall.

Multiple appearances of the non-typical cells are recognized in the single glandular tubule which is poorly developed and is not surrounded by the fibrous capsule. Such a tubule exists independently of the distribution of the well-developed apocrine tubules. Moreover, the grouped non-typical cells reveal themselves in the tubules near the excretory duct. Several non-typical cells are encountered in the tubules of the well-developed glandular bodies that have no definite fibrous capsules, especially in the tubules near the excretory duct. The excretory ducts which belong to the glandular bodies with non-typical cells in them demonstrate a little different profils, when compared with those of the frequently encountered ducts. Namely, the cells of the inner layer are varied in size and are arranged irregularly, though they line in a line as the normal excretory ducts do. The luminal cytoplasm of some cells is occasionally protruded into the lumen, as if the epithelial cells underwent apocrine-like secretion. In occasional cells of the inner layer, PAS-positive substances considered to be glycogen are piled up in some parts of the cytoplasm. The nuclei alter their size from cell to cell, demonstrating round, elliptic and spindle-like appearance. Sometimes the cells of the inner layer have elongated triangular nuclei which are suggestive of those of the eccrine glandular cells. The coloration obtained after the hematoxylin staining varies in each cell of the inner layer. 
The inner layer of the excretory duct is, on occasion, covered by two layers of the cells, in opposition to the normal arrangement of the inner epithelial cells. Regarding the outer layer of the excretory duct, it is consisted of the cuboidal or flattend cells with elliptic shaped nuclei and provided with great accumulation of glycogen in the cytoplasm, but on the other hand, it is partly consisted of flattened cells with markedly flattened nuclei. This lining of the flattened cells shows gradual transitional tendency to the myoepithelial cell layer. Occasional cells in the outer layers, occur between the basal parts of two inner layer cells, as if they were pinned under the inner layer cells. In such an excretory duct as mentioned above, the inner layer cells present a similar figure to that of the dark cells of the eccrine gland and attach to the basement membrane with narrow cytoplasmic stalks. These figures are suggestive of the apocrine-like secretory action of the inner layer cells at the transitional part from the glandular tubule to the excretory duct. Moreover, these figures give the impression that the outer layer cells or the cells at the part where the outer layer alters into the myoepithelial cell layer have the possibility to deviate from the normal situation and appear in the interspaces between each inner layer cell.

It is sometimes encountered that several cells of the inner layer are provided with glycogen, unlike the normal state of the inner layer cells.

From the fact described above, it is conjectured that the transitional portion between the secretory tubule and the excretory duct is very unstable in the arrangement of the epithelial cells. Besides, it is worthy of note that the unstable arrangement of the cells in the excretory duct is frequently visualized, when a secretory tubule possesses some mixed non-typical cells in its glandular epithelium.

2) The tall lozenge-shaped cells which are discovered between two apocrine glandular cells in the apocrine tubules.

This kind of cells presents narrow lozenge-shaped profils and attach, with linear stalks of the cytoplasm, to the basement membrane. The cells are mostly as tall as and sometimes a little lower than the other apocrine glandular cells. They have the elliptic-shaped nuclei which are by far smaller in size than those of the typical apocrine cells. The nucleoli are rather large, not in proportion to the size of the nuclei. The cytoplasm is stained remarkably darker than those of the typical apocrine cells. The small granules are 
scattered in the supra-nuclear area of the cytoplasm, though the large granules are never encountered at anywhere. The PAS reaction occurres uniformly in the cytoplasm and is stronger than in the typical apocrine cells. These non-typical cells are markedly stained by thionin, notwithstanding the negative results in the typical apocrine cells. These cells are exclusively encountered in the apocrine tubules lined by the tall columnar cells. They tend to appear at the portions where the glandular wall demonstrates unevenness and the irregular arrangement of the epithelial cells is noticed.

The occurrence of the two kinds of the non-typical apocrine cells is related to the distribution of neither hair follicles nor eccrine sweat glands, with the exception of a case, in which the multiple occurrence of the non-typical cells is recognized. Such an apocrine tubule as is revealed itself adjacent to the eccrine glandular body.

The difference of the probability in the occurrence of both kinds of non-typical cells is not statistically examined, but it may be easily presumed even from the histological survey that the former cells are as far frequently confronted.

The personal difference is significantly noticeable in the occurrence of both kinds of the non-typical cells.

\section{Discussion}

There have been several reports with respect to the non-typical cells appeared in the sweat glands. M i n a m it a $\mathrm{n}$ i (1941-a) devided the apocrine sweat glands occurred in the axillary region of the human kind into four types; namely typical, non-typical A, nontypical $B$ and mixed glands.

The non-typical apocrine gland A consists of narrow glandular cells with elongated elliptic-shaped nuclei, containing coarse large secretory granules in few number in the cytoplasm. The glandular cells arrange themselves regularly in a line and are endowed with no intercellular canaliculus between them. M i n a mit a $\mathrm{n}$ i suspected that this kind of the glands might be the underdeveloped apocrine glands, though they undergo the active secretory function. The nontypical apocrine gland $B$ has a little smaller glandular body than the typical one but is provided with the dilated lumen.

The appearance of the glandular tubules of this type coincides with that of the apocrine gland in the next regards that the glandu- 
lar cells line up regularly in a line and have no intercellular canaliculi between them. Nevertheless, the glandular cells resemble those of the luminal cells of the eccrine glands, that is to say, the epithelial cells present smaller columnar shape than those of the apocrine cells. The small-sized secretory granules are very few in number and often lacking, and the nuclei are generally smaller than those of the apocrine glands and have more than two nucleoli. Min a mita ni regarded these two kinds of the non-typical glands $(\mathrm{A}, \mathrm{B})$ as the intermediate type between eccrine and apocrine glands. The mixed sweat gland, on which Minamita $\mathrm{n}$ i reported, is the eccrine secretory tubules which are partly covered by the apocrine glandular cells and have dilated lumen. In these tubules, the luminal cells of the eccrine portion demonstrate clear images that are similar to those in the apocrine glandular cells, though the clear cells of the eccrine portion give the same clear appearance as those in the typical eccrine gland and possess the intracellular and intercellular canaliculi between each of them.

In this study, only the non-typical gland $B$ and the mixed gland are frequently encountered. The cell which belongs to the nontypical gland is strongly reactive to the PAS routine. The secretory processus protruded into the lumen and the luminal contents are also intensely stained by PAS method. The non-typical gland B is not found in the glandular bodies of the typical apocrine glands, but in the neighborhood of the eccrine tubules or sometimes in the eccrine glandular bodies, within the range of this study. The size of the lumen varies from wide to narrow, according to each tubule. The myoepithelial cells are well developed, when compared with those of the typical eccrine and apocrine glands. This figure suggests that this type of glands may carry out the intense secretory function.

The mixed glands are also encountered in this study. The epithelial constitution of this gland is considered to indicate that the clear cells of the eccrine gland are replaced by the luminal cells of the same gland, as I to et al (1956) have reported on the perianal gland at the mixed portion, all the epithelial cells arrange themselves in one layer, regardless of their origin. The supposed luminal cells are negatively reactive to the PAS routine and project small secretory processus into the lumen, while the supposed clear cells are strongly positive to the PAS method as in the typical clear cells and stand in a row with the luminal cells. Occurring in close 
proximity to the basement membrane, non-typical cells which are mentioned in this report are recognized between the basal parts of the epithelial cells, without facing the lumen.

I to et al (1956) insisted the propriety of the hypothesis, which is contradictional to the opotunity of Schiefferdecker, that there is the intermediate type of the sweat gland between eccrine and apocrine sweat glands, judging from the results obtained from the investigation of $I$ to et al (1956, perianal and nasal glands) and Ot a (1950, human axillary gland). He asserted that the apocrine gland is the primitive skin organ and more numerously encountered according as the order of the animals descends, while the eccrine gland is phylogenetically in more developed stage than the former and appear few in number in the lower animals and mostly in monkey and human kind. He, after all, considered that the gradual alteration from the apocrine gland to the eccrine gland must be took place in the long course of the phylogenetic ascension. If the hypothesis offered by I to were reliable, the non-typical cells which are reported in this study must be the clear cells of the eccrine gland. Whereas they are somewhat different from the clear cells in the histochemical property, as described above. They are presumed to be in the younger or undeveloped stage of the clear cells, because they are provided with both nucleic acid and glycogen at the same time in their cytoplasm, unlike the matured clear cells which contain only glycogen but almost no nucleic acid. If the hypothesis of I to were true, the apocrine glandular tubules with the deviated nontypical cells in the arrangement of the epithelial cells must be phylogenetically in higher order than the apocrine tubule covered with only typical apocrine cells. But, in this study, the multiple occurrence of the non-typical cells is recognized always in the underdeveloped or the simply coiled apocrine tubules. In other words, the cells in the course of the phylogenetical ascendence appear in the underdeveloped tubules. Accordingly, it would be concluded that the occurrence of the non-typical cells in the apocrine tubules may be one of the signes of the phylogenetical ascendence in the long course of the history of the animals but it does not always exactly fit the case in each person or each tubule. So far as the origin of the mixed sweat gland is concerned, I to et al (1956) presumed that some apocrine gland might degenerate into disappearance but others could be transformed into the eccrine glands, considering the existence of the mixed gland. The possibility of the transformation 
from the apocrine glandular cells into the dark or luminal cells of the eccrine gland is rather easy to understand than that from the apocrine glandular cells into the clear cells of the eccrine gland, because the nature and the appearance of the apocrine cells are similar to those of the dark cells. As the nature and the form of the clear cells of the eccrine gland are quite different from those of both apocrine cells and clear cells, the presence of the non-typical cells (the younger form of the clear cells) and the number of these cells in a tubule are the important factors to decide the degree of the mixture of the mixed sweat gland. Regarding the origin of the clear or nontypical cells, it is considered with in the range of this study that the myoepithelial cells give rise to them. Because they are very low and situate adjacent to the basement membrane and the gradual increase of the cell size and the glycogen accumulation in the myoepithelial cells is visualized in the neighbourhood of the non-typical cells. Besides, it may be possible to presume that the stimulation of the luminal contents or sweat constituents to the myoepithelial cells could urge the metamorphosis of the myoepithelial cells into the non-typical apocrine cells or the clear cells of the eccrine gland, considering from the fact that these cells appear at the apecies of the protrusion of the glandular epithelium or at the apical part of the luminal projection between the apocrine glandular cells. I to et al pointed out more crowded distribution of myoepithelial cells in the apocrine tubule than the eccrine gland and asserted the possibility of the alteration from the myoepithelial cells into the clear cells of the eccrine gland. The opinion offered by $\mathrm{I}$ to et al is also agreeable in this study, together with the presumption of metamorphosis stimulated by the luminal contents, as mentioned above.

As the other possibility of the origin, I to et al indicate the alteration from the apocrine glandular cells to the mixed clear cells. They reported the presence of the clear cells faced the lumen and provided with intercellular canaliculi between each of them, in the apocrine epithelial arrangement and imagined the possibility of the transformation of the apocrine cells into the clear cells. They did not refer to the height of these clear cells and to the results of the PAS reaction. The non-typical cells mentioned in this study are intensely reactive to the PAS routine and far lower in height than the surrounding apocrine cells. It is doubtful that the clear cells which I to et al have previously reported may correspond to the non-typical cells alluded in this study. Of course, the tall apocrine cells with great 
accumulation of the PAS-positive substances in their whole cytoplasm are rarely encountered. But, it is questionable that these cells may coincide with the clear apocrine cells which Ito et al reported. Moreover, the transitional profils from the tall, PAS-positive apocrine cells to the low, PAS-positive clear or non-typical cells are never visible within the range of this study. Therefore, it needs further examination to make clear whether the clear cells or non-typical cells originate from the apocrine glandular cells or not.

The next possibility to be presumed is that the metamorphosis may begin at the transitional part from the secretory tubule to the excretory duct.

As indicated above, the multiple occurrence of the non-typical cells is often recognized in the underdeveloped or simply coiled apocrine tubule. In the epithelium of the excretory duct which belongs to such an underdeveloped tubule as mentioned already, the arrangement of the epithelial cells in two layers is disordered and the cells of the inner layer present the appearance similar to the epithelial cells of the secretory tubule. These findings coincide to those described by I to and En jo (1949). Occasionally, some cells of the outer layer intervene between the cells of the inner layer and they are still provided with glycogen, inspite of the disarrangement. The lining of the cells in the outer layer is also partly out of order.

They look like the myoepithelial cells in their appearance but contain slight amount of glycogen, unlike the ordinary myoepithelial cells. From these figures observed in the excretory duct, it may be imagined that the non-typical cells begin to wedge themselves into a line of another kind of cells on the transitional part from the excretory duct to the secretory tubule and that the non-typical cells originated presumably from the myoepithelial cells appear in the secretory portion in the same way as in the excretory duct, where the cells of the outer layer continued gradually from the myoepithelial layer squeeze themselves into a line of the inner layer cells.

\section{Conclusion}

The non-typical cells occurred in the apocrine tubules of the human axillary skin were histologically and histochemically observed in this study.

I) Low cells which break into a line of the apocrine glandular 
cells, occurring adjacent to the basement membrane.

The appearance of these cells was similar to that of the clear cells of the eccrine gland. They were clearly stained with iron hematoxylin and contained great amount of glycogen. Whereas some of these cells were intensely stained with thionin and strongly positive to the alkaline tetrazolium reaction, unlike the clear cells of the eccrine gland. Some of these non-typical cells were considered to be in the younger or underdeveloped stage of the clear cells.

They appeared in the apocrine tubule in five manner mentioned below. 1) Some of them occurred in the close proximity to the basement membrane and never face the lumen. 2) Some of them were visualized at the bottom of the epithelial depression, where the lumen projected deeply between the epithelial cells. The cells in this item face the lumen, without exception. 3) Some of them situated at the apical part of the convex surface of the glandular wall protruded into the dilated large lumen, and fronted on the glandular lumen. 4) Some of them were encountered at the bottom of the depressed part of the epithelium, where, correspondingly to the depression of the epithelium, the glandular wall projected towards outside. They often bordered directly on glandular lumen, but occasionally were buried under the surrounding apocrine cells. 5) Sometimes, the cells which referred to the foregoing four items appeared simultaneously in a single apocrine tubule.

The cells which belong to 1 st-4th sub-items occurred exclusively in the well developed glandular bodies surrounded by the definite fibrous capsules. They revealed themselves singly in the transverse sections of several tubules in a single glandular body. While, those belong to 5th sub-item were recognizable multiplicably in a single underdeveloped or simply coiled apocrine tubules which were not surrounded with the fibrous capsule.

II) Tall lozenge-shaped cells which are discovered between two apocrine glandular cells in the apocrine tubule.

This kind of cells presents narrow lozenge-shaped profils and attached to the basement membrane, with linear stalks of the cytoplasm. They were stained remarkably darker with iron hematoxylin than the typical cells and contained small secretory granules but no large ones. They abounded in nucleic acid, notwithstanding the low concentration in the typical apocrine cells. These cells had tendency to appear at the portions where the glandular wall demonstrated unevenness and was disarranged by the epithelial cells. 
III) The cells which were mentioned in the first item were more frequently encountered than those in the second item.

IV) In the occurrence or in the frequency of the appearance of these non-typical cells, personal difference was remarkably recognized.

V) Some of the cells of the outer layer seemed to cut into the inner layer of the excretory duct which belong to the secretory tubule provided with the occasional non-typical cells in their glandular epithelium.

VI) Regarding the origin of the non-typical cells, it was possibly presumed that the myoepithelial cells gave rise to or the apocrine glandular cells altered into the cells concerned. Within the range of this study, the former possibility might be reliable, as the presumably intermediate type of cell between the myoepithelial cell and the non-typical cell were often visible near the proper cells. But this problem must be decided after the careful examination in many histological and embryological specimens.

VII) The occurrence of the non-typical cells in the apocrine tubules might be indicative of one of the evidences of the phylogenetical ascendence in the long course of the history of the animals, but it would not always exactly fit the case in each person or each grandular tubule.

It is a pleasure to record my sincere thanks to Prof. Dr. T. T a$\mathrm{ni} \mathrm{g} \mathrm{u} \mathrm{ch}$ for his kind criticism and helpful guidance.

\section{References}

1) Cormia, F.F. and V. Kuykenda11: Cytochemical studies on eccrine sweat tubules: Cellular differentiation and glycogen content.

Journal of Investigative Dermatology, Vol. 24, No. 5, P. 527, 1955.

2) Ito, T. and K. Enjo: Cytological study on the excretory ducts of the sweat glands. On the transitional part from the secretory tubule to the excretory duct, with special reference to the apocrine-like secretory modus. Science of the living body, Vol. 1, No. 2, P. 69, 1949 (Japanese).

3) It o, T., Y. Narita, K. Tsunoda and K. Shindo: Über das Vorkommen von "gemișchten" Schweissdrüsen in Perianal und Nasenflügelhaut des Menschen. Arch. hist. jap., Vol. 10, No. 3, S. 381, 1956 (Japanisch).

4) Ito, T. and K. Tsunoda: On the occurrence of the mixed sweat gland in the human perianal skin. Kaibogaku Zassi, Vol. 31, No. 1, P. 108, 1956 (Japanese).

5) $\mathrm{M}$ in amitani, K.: Zytologische und histologische Untersuchungen der Schweissdrüsen in menschlicher Achselhaut. Über das Vorkommen der besonderen Formen der apokrinen und ekkrinen Schweissdrüsen in Achselhaut von Japanern. Okajimas Fol. anat. jap., Band 20, Heft 5-6, 1941-a.

6) Ota, R.: Zytologische und histologische Untersuchungen der apokrinen Sch- 
weissdrüsen in den normalen, keinen Achselgeruch (Osmidrosis axillae) gebenden Achselhäuten von Japanern. Arch. hist. jap., Vol. 1, No. 3, s. 285, 1950 (Japanisch).

7) Pe a rse, A.G.E.: The histochemical demonstration of cystine containing structures by method involving alkaline hydrosis. J. histochem. and cytochem., Vol. 1, No. 6, P. 460, 1953.

8) - Application of the alkaline tetrazolium reaction to the study of reducing groups in tissue sections. J. Path. and Bact., Vol. 67, P. 129, 1954.

9) - Histochemistry, Theoretical and Applied. P. 54. J. \& A. Churchill Ltd., London. 1954.

\section{Explanation of Figures}

Fig. 1. This photograph illustrates two non-typical cells, seemingly grew up with a common cytoplasmic stalk from the same place of the basement membrane. One contain greater accumulation of glycogen than the other. At the left side of two non-typical cells, a cell surrounded by the fiber which reacts to the PAS routine is recognized. The myoepithelial cells in the neighbourhood of these three cells are generally enlarged and occasionally contain the trace of glycogen. The lumen protrudes deeply into the epithelial depression. The non-typical cells appear at the bottom of the epithelial depression. The epithelial cells surrounding the non-typical cells are the typical aporcine glandular cells provided with large secretory granules which are strongly reactive to the PAS routine.

Fig. 2. The non-typical cell is recognized at the bottom of the gradual depression of the epithelim.

Fig. 3. This figure indicates a non-typical cell at the basal part of the epithelium. It does not front on the lumen. The enlarged myoepithelial cells are visualized in the neighbourhood of the non-typical cells.

Fig. 4. A non-typical cell which is reactive to the PAS method situates at the apex of the convex surface of the epithelial wall. The myoepithelial cells near the cells concerned enlarged their size.

Fig. 5. This figure gives the multiple occurrence of the non-typical cells in a single apocrine tubule. A myoepithelial cell is seen at 9 o'clock, enlarged itself but is unreactive to PAS method. Some of the non-typical cells face the lumen which is deeply break in the epithelial layer.

Fig. 6. This picture reveals six low non-typical cells which are PAS:positive and continuously arranged along the convex surface of the basal membrane. They present similar profils to the myoepithelial cells. Only two of them border on the lumen.

Fig. 7. The multiple occurrence of the non-typical cells is recognized in a apocrine tubule. Some of them open out on the lumen.

Fig. 8. This monograph presents the figure of a mixed sweat gland. The PASnegative cells resemble the dark cells of the eccrine gland, while the PAS-positive cells do the clear cells.

Fig. 9. This specimen is stained with thionin. A long lozenge-shaped cell is more darkly stained than the typical apocrine cells in the surroundings. The negative image of the Golgi apparatus is clearly observed in the dark cell. Several granules in small size are encountered in the cytoplasm. The nucleus is small in size, elliptic shaped and provided with a nucleolus 
which is larger than that of the apocrine cell.

Fig. 10. A cell that is intensely stained with thionin is visible adjacent to the basement membrane of the apocrine tubule at the direction of 11 o'clock. This cell coincides with that which is strongly positive to the PAS method. Whereas, the clear cell of the eccrine gland is PAS positive but hardly stained with thionin, though it is not visualized in this picture.

Fig. 11. This picture indicate the transitional part from the secretory tubule to the excretory duct of the apocrine tubule which is underdeveloped and wedged by multiple non-typical cells. The cells in both inner and outer layers are disordered in their arrangement. Some PAS-positive cells which come probably from the outer layer are noticed in the inner layer. Some of the cells in the outer layer are difficult to be differentiated from the myoepithelial cells.

Fig. 12. This figure illustrates a specimen stained by the alkaline tetrazolium reaction. A cell which is piled up with yellow-brown granular structures at the centre of this picture corresponds to the non-typical cell. While the clear cell of the eccrine gland presents scarsely any reaction to this method, if refered to for information. 
Plate I
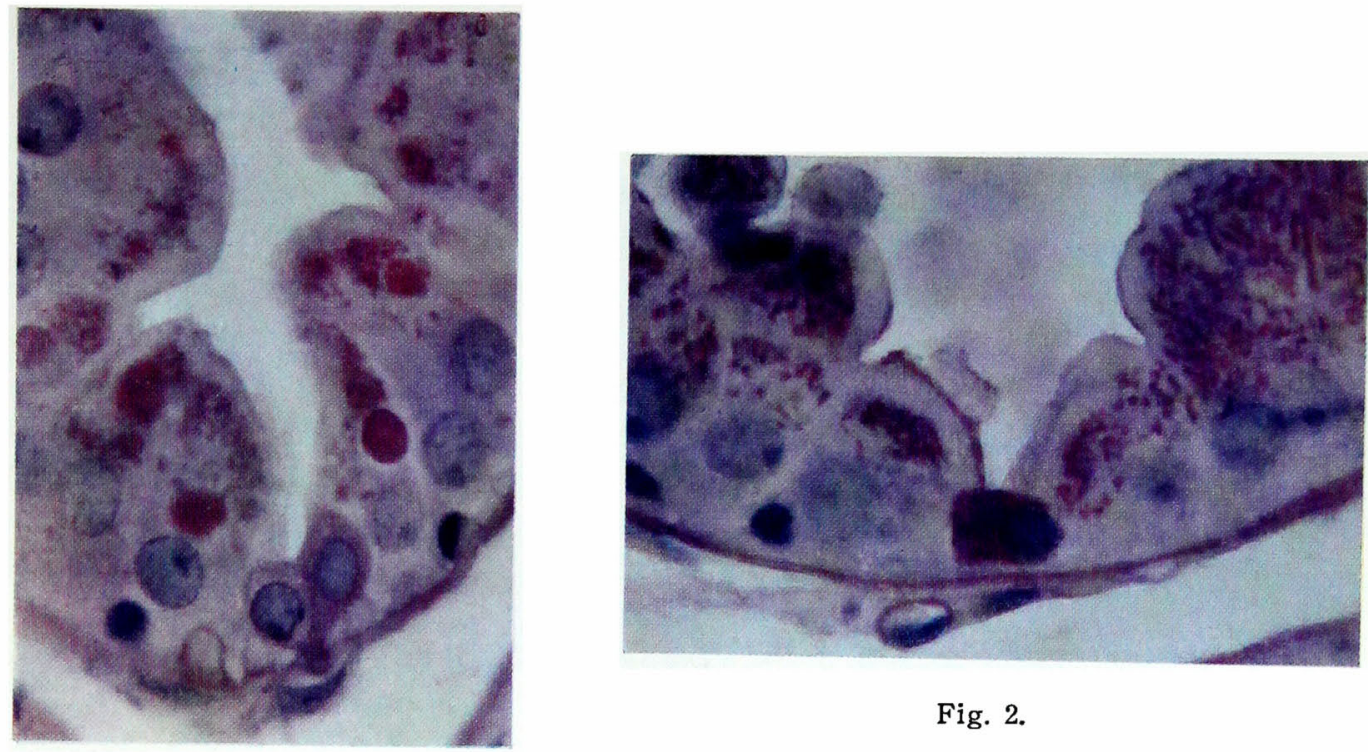

Fig. 2.

Fig. 1.

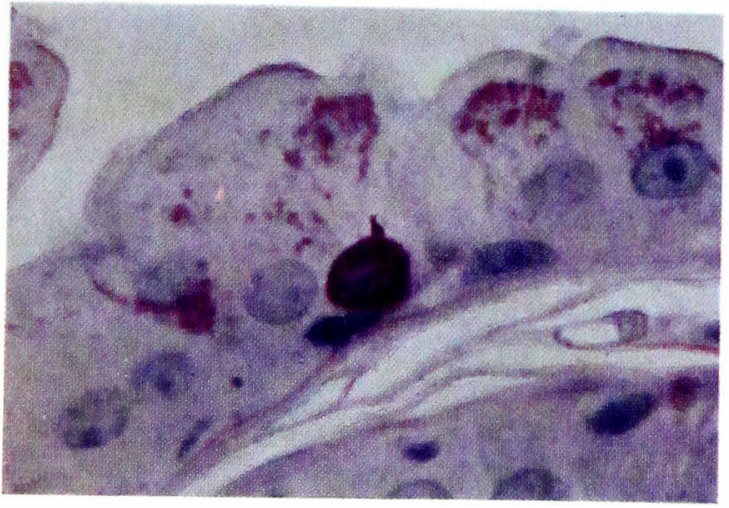

Fig. 3.

K. Yasuda

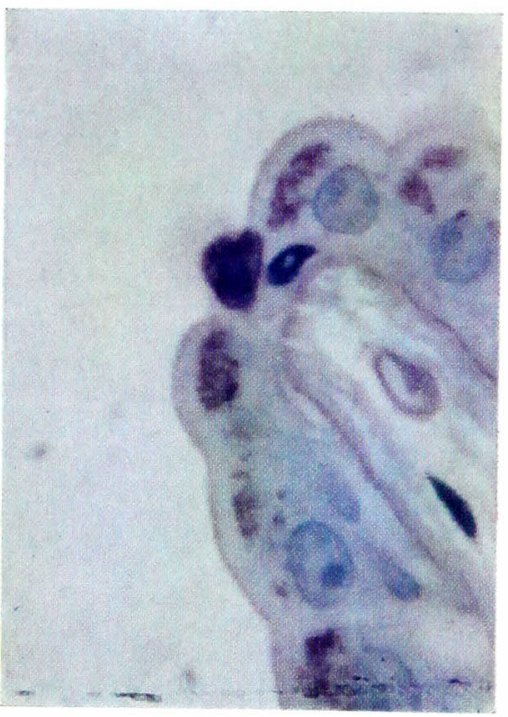

Fig. 4. 
Plate II

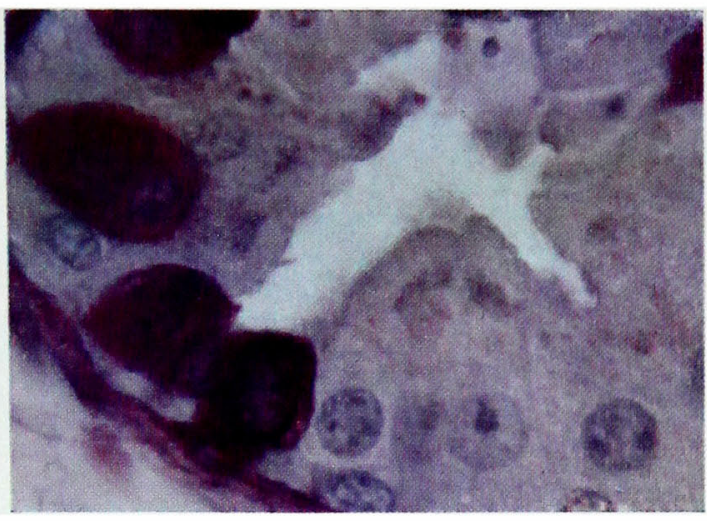

Fig. 5.

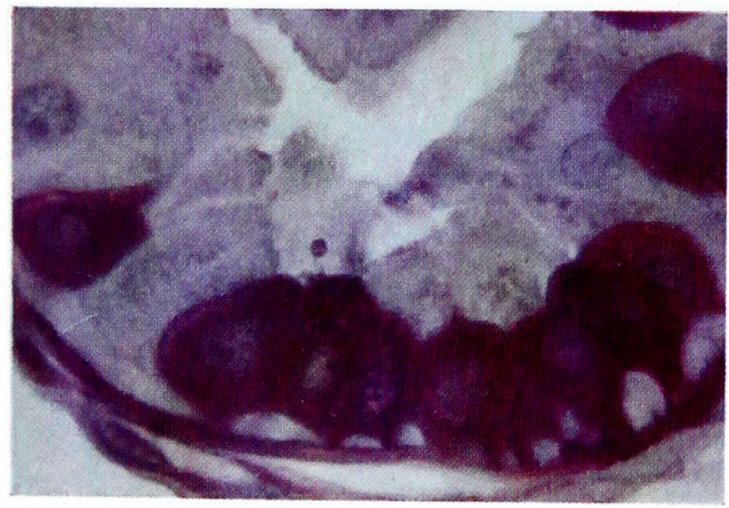

Fig. 7.

K. Yasuda

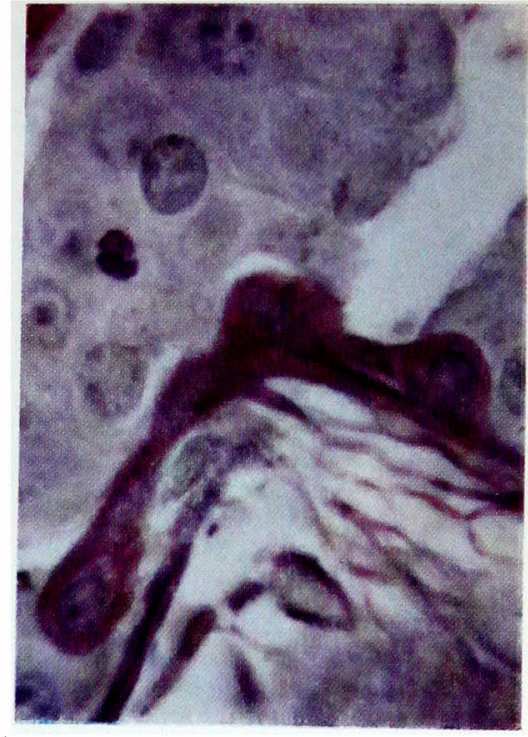

Fig. 6

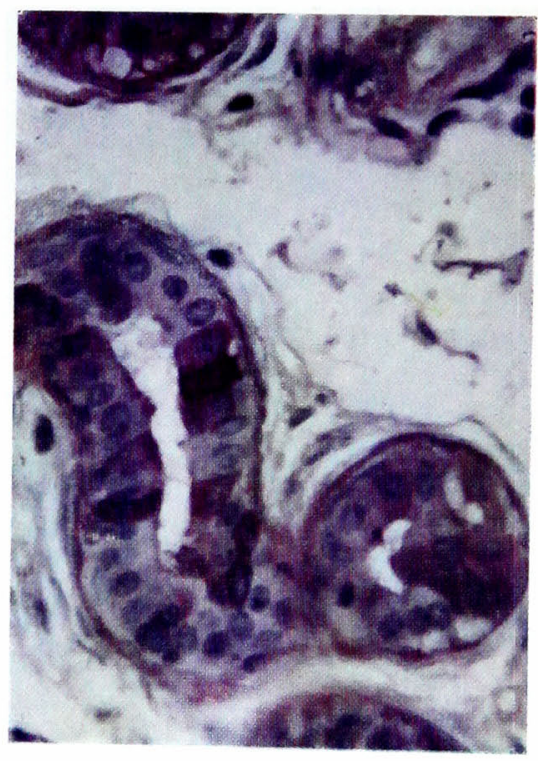

Fig. 8. 
Plate III

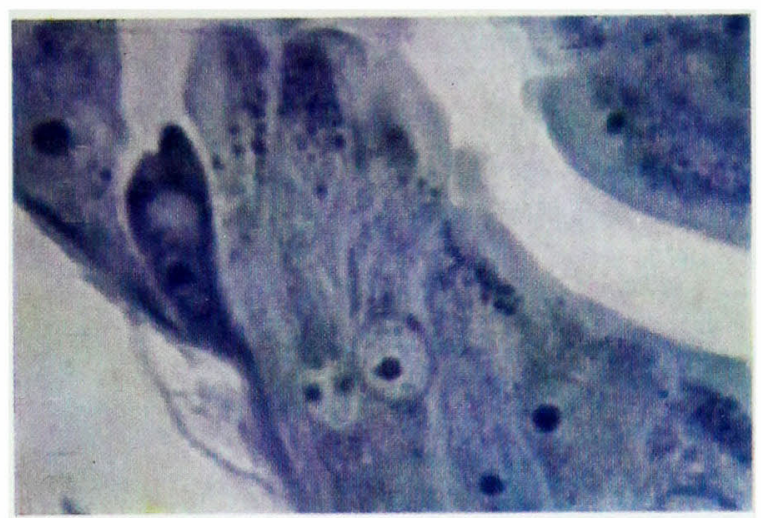

Fig. 9.

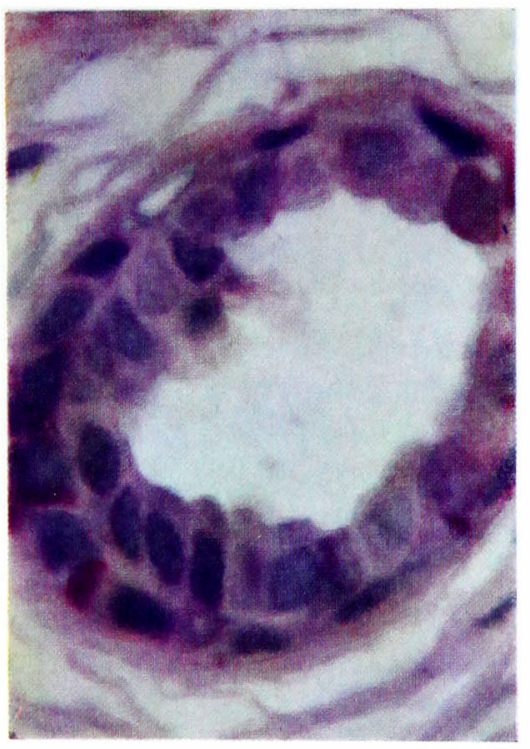

Fig. 11.

K. Yasuda

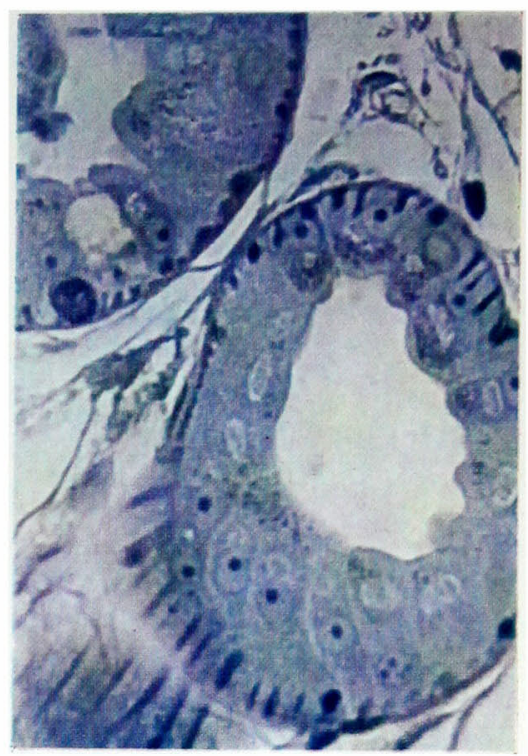

Fig. 10 .

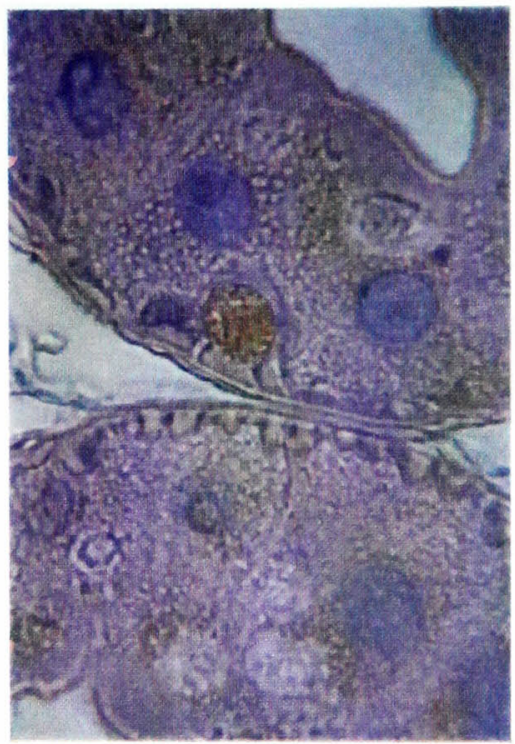

Fig. 12. 